\title{
Numerical Study of Natural Convection Heat Transfer from a Horizontal Plate using Solid, Hollow and Hollow/Perforated Pin Fins
}

\author{
A. H. Mousa \\ Nile Higher Institute for Engineering and Technology, Mansoura, Egypt \\ E-mail: ahmousa14@gmail.com
}

\begin{abstract}
Natural convection heat transfer from circular solid, hollow and hollow/perforated pin fin arrays with different geometry is studied numerically using ANSYS 16.0. The geometric dependence of heat transfer from heat sinks of solid, hollow and hollow/perforated fins with staggered arrangement, involved on a fixed area heated base plate is discussed. To solve governing equations (mass, momentum and energy), a SIMPLE code is developed using control volume approach. The second order upwind technique is used. The results were performed for a range of Rayleigh number, $9.3 \times 10^{6}<\mathrm{Ra}<1.63 \times 10^{7}$. It presented that the performance of the solid fin heat sink is higher than the hollow ones and $\mathrm{Nu}$ for the hollow/perforated fin heat sink is higher than that for the solid fin heat sink. It is also investigated that hollow/perforated fin array with inner-to-outer diameter ratio $\left(D_{i} / D_{o}=1 / 2\right)$ and perforation diameter $\left(d_{p}=6 \mathrm{~mm}\right)$ is the best sample giving the maximum performance and less amount of weight compared to the corresponding solid ones.
\end{abstract}

Keywords: Perforated/hollow pin fin, Heat sink, Nusselt number, Computational Fluid Dynamics.

\begin{tabular}{|l|l|l|l|}
\hline \multicolumn{2}{|l|}{ Nomenclature } & \multicolumn{2}{l|}{ Greek symbols } \\
\hline A & surface area, $\mathrm{m}^{2}$ & $\alpha$ & thermal diffusivity of air, $\mathrm{m}^{2} / \mathrm{s}$ \\
\hline $\mathrm{D}$ & pin fin diameter, $\mathrm{mm}$ & $\beta$ & $\begin{array}{l}\text { coefficient of thermal } \\
\text { expansion of air. } \mathrm{K}^{-1}\end{array}$ \\
\hline $\mathrm{d}_{\mathrm{p}}$ & perforated diameter, $\mathrm{mm}$ & $\varepsilon$ & emissivity, - \\
\hline $\mathrm{G}$ & gravity, $\mathrm{m} / \mathrm{s}^{2}$ & $\mu$ & dynamic viscosity, Pa.s \\
\hline $\mathrm{H}_{\mathrm{f}}$ & pin fin height, $\mathrm{mm}$ & $v$ & kinematic viscosity, $\mathrm{m}^{2} / \mathrm{s}$ \\
\hline$\overline{\mathrm{h}}$ & average convective heat & $\rho$ & density, $\mathrm{kg} / \mathrm{m}^{3}$ \\
\hline $\mathrm{K}$ & thermal conductivity, $\mathrm{W} / \mathrm{m} \mathrm{K}$ & $\Psi$ & finning factor, - \\
\hline $\mathrm{L}$ & base plate length, $\mathrm{m}$ & \multicolumn{2}{|l|}{ Subscripts } \\
\hline $\mathrm{N}$ & number of pin fins,, & b & base plate \\
\hline
\end{tabular}




\begin{tabular}{|l|l|l|l|}
\hline$\overline{\mathrm{Nu}}$ & average Nusselt number, - & $f$ & Fin \\
\hline $\mathrm{P}$ & pressure, $\mathrm{Pa}$ & $\mathrm{fp}$ & projected fin \\
\hline $\mathrm{Q}$ & heat transfer rate, $\mathrm{W}$ & $\mathrm{fm}$ & mean fin \\
\hline $\mathrm{Ra}$ & Rayleigh number, - & $\mathrm{h}$ & horizontal \\
\hline $\mathrm{S}$ & fin spacing, $\mathrm{mm}$ & $\mathrm{i}$ & inside \\
\hline $\mathrm{T}$ & temperature, $\mathrm{k}$ & $\mathrm{m}$ & film \\
\hline $\mathrm{u}, \mathrm{v}$, & velocity components in $\mathrm{X}, \mathrm{Y}, \mathrm{Z}$ & $\mathrm{o}$ & Outside \\
\hline $\mathrm{V}$ & volume, $\mathrm{m}^{3}$ & $\mathrm{~s}$ & mean surface \\
\hline $\mathrm{W}$ & base plate width, $\mathrm{mm}$ & $\mathrm{t}$ & Total \\
\hline $\mathrm{X}, \mathrm{y}$, & rectangular coordinates & $\mathrm{v}$ & Vertical \\
\hline
\end{tabular}

\section{Introduction}

Natural convection is widely used because it doesn't require a power supply for a fan and high reliability. For enhancing heat transfer from system components in industry to prevent the destructive effects due to overheating, extended surfaces are used. Pin fins are used in various applications such as cooling electronic and thermoelectric devices, heat exchangers and solar energy applications, ...etc. The optimization of fins size and modification of their shapes play an important role to achieve minimum cost, weight and size and also increase the rate of heat dissipation. A lot of research work has been conducted to study the effect of geometry and operating parameters on the heat transfer mechanism. AlEssa et al. [1] compared the heat dissipation enhancement from a perforated horizontal rectangular fin under natural convection. They realized that the perforated horizontal rectangular fin gives more heat transfer and a reduced amount of weight compared to corresponding solid fins. Elshafei [2] experimentally studied natural convection heat transfer from the circular pin fin heat sink and compared it with perforated. He observed that in the case of perforated fin heat sink, Nusselt number of upward arrangement was lower than sideward arrangement. Bahadure et al.[3] experimentally studied the thermal performance of a pin fin heat sink made from copper, aluminum and mild steel with a number of perforations on the pin fin. They observed that the average heat transfer coefficient is higher for three perforations compared to solid, single, and two perforations respectively. Murtadha et al.[4] studied natural convection heat transfer through solid and perforated square pin fin heat sinks. They observed that the perforated pin fin gives better heat transfer than solid pin fin. Awasarmol et al. [5] investigated the heat transfer characteristics of perforated pin fin array in natural convection by changing the perforation diameter from 4-12 $\mathrm{mm}$ and inclination angles from 0 $90^{\circ}$. They observed that fins with $12 \mathrm{~mm}$ diameter of perforation present greater heat transfer at an angle of $45^{\circ}$. Al-Widyan et al. [6] studied numerically the enhancement of heat dissipation for a perforated fin in natural convection.. They found that the heat transfer increased as the spacing between holes decreased. Senol, et.al. [7] carried out a parametric study to investigate the effect of fin spacing, fin length, fin height and concluded that overall heat transfer is superior with the decrease in fin length and the increase in fin height, hence increases with H/L. Al-Essa et al. [8] investigated the natural convection heat transfer augmentation from triangular perforated horizontal rectangular fin. They found that temperature drop alongside the solid fin length is lower 
than that on the equivalent perforated fin. Hanamant et.al. [9] numerically and experimentally evaluated natural convection heat transfer and fluid flow characteristics of fin array with lateral circular perforation, equipped on the horizontal flat surface. They concluded that heat dissipate increases with the increase in the size of perforation. Welling et al. [10] discussed the effect of change in the fin height-to-fin spacing ratio $\left(\mathrm{H}_{\mathrm{f}} / \mathrm{S}_{\mathrm{r}}\right)$ on the variation of temperature then proposed the optimum value equation for $\left(\mathrm{H}_{\mathrm{f}} / \mathrm{S}_{\mathrm{r}}\right)$. Their results showed that the vertical orientation of fin array is the most efficient including all other types. Chaddock [11] varied the fin height and its spacing in the large vertical fin arrays and deduced that about $20 \%$ of the total heat transfer is contributed by the radiation heat transfer. Naik et al. [12] experimentally studied the natural convection heat transfer from heat sink with a vertical rectangular fin with a horizontal shroud situated adjacent to and above the fin tips. They found that the increase in the ratio of the shroud clearance to fin height from (0 to 1$)$ resulted in a higher heat transfer rate from the heat sink. Leung [13] studied the heat transfer from polished duralumin vertical rectangular fins and found that the optimum thickness of fins was from $20 \mathrm{~mm}$ to $60 \mathrm{~mm}$. Ko et al. [14] experimentally studied the heat transfer from vertical rectangular fin array made from stainless-steel under natural convective conditions. They concluded that the optimum fin spacing relating to changes in temperature excess from 20 to $40{ }^{\circ} \mathrm{C}$. Natural convection and radiation heat transfer from a heat sink with five staggered cylindrical pin fins were experimentally studied by Sparrow and Vemuri [15]. They found that the radiation was a dominant factor and contributing $25-40 \%$ of the total heat transfer. Alessio et al. [16] experimentally investigated the natural convection and radiation heat transfer from a heat sink of inclined staggered fins with inclination angles of $30^{\circ}$ and $60^{\circ}$ down from the horizontal. They reported that the rate of heat transfer decreased by $10 \%$ lower than the horizontal array. Zografos and Sunderland [17] studied natural convection and radiation from pin fin arrays which were arranged inline and staggered. It was presented that the inline arrangements presented higher heat dissipation rate than the staggered ones. Huang et al. [18] experimentally investigated the natural convection heat dissipation from pin fin heat sinks subjected to the effect of orientation. They found that the downward facing orientation gave a lower heat transfer coefficient than sideward and upward orientation. Bahadur and Cohen [19] carried out an optimization of natural convection fin arrays formed of polyphenylene sulphide polymer. They found that the geometrical parameters were the dominant factor affecting the heat dissipation rate.

From the previous review, many researchers deal with the heat dissipated from heat sink but a very little of them deal with the hollow perforated pin fins relaying on natural convection mode. So, the present work deals with the natural convection heat transfer performance of solid, hollow and hollow perforated pin fin heat sinks and also studied the heat sink performance of pin fin diameter ratio $\left(D_{i} / D_{o}\right)$ and perforation diameter $\left(\mathrm{d}_{\mathrm{p}}\right)$ variation effect for horizontal base plate orientation.

\section{Numerical method}

\subsection{Physical Model}

In this study, a perspective view of heat sinks are composed of an array of eight (a) solid pin fins, (b) hollow pin fins, (c) hollow/perforated pin fins and (d) top view of heat sink are shown in Fig.1. The base plate of the heat sink is $150 \mathrm{~mm}$ wide, $150 \mathrm{~mm}$ long and $10 \mathrm{~mm}$ thickness. For the heat sinks, each fin is $50 \mathrm{~mm}$ long, $12 \mathrm{~mm}$ outer diameter, inner-to-outer diameter $\left(\mathrm{D}_{\mathrm{i}} / \mathrm{D}_{\mathrm{o}}=1 / 3,1 / 2,2 / 3\right)$ and perforation diameter $\left(\mathrm{d}_{\mathrm{p}}=3.5,4,5,6 \mathrm{~mm}\right)$. The heat sink was made of aluminum $(\mathrm{k}=237 \mathrm{~W} / \mathrm{m}$ $\mathrm{K})$. Pin fins were arranged in a staggered manner with inter-fin spacing ratios of $\left(\mathrm{S}_{\mathrm{h}} / \mathrm{D}_{\mathrm{o}}=3.5\right.$, $\left.\mathrm{S}_{\mathrm{v}} / \mathrm{D}_{\mathrm{o}}=5\right)$. The perforated hole was at $5 \mathrm{~mm}$ from the base plate of the heat sink. Detailed dimensions of investigated heat sink samples are listed in Table 1. 


\subsection{Data reduction}

The finning factor $\Psi$ is defined as:

$$
\begin{aligned}
& \Psi=A_{t} / A_{b p} \\
& A_{b p}=\mathrm{WL}-A_{f p} \\
& A_{f p}=N\left[\frac{\pi}{4}\left(D_{o}^{2}-D_{i}^{2}\right)\right] \\
& A_{t}=A_{b p}+A_{f} \\
& A_{f}=N\left[\frac{\pi}{4}\left(D_{o}^{2}-D_{i}^{2}\right)+\pi\left(D_{o}+D_{i}\right) H_{f}+\pi\left(D_{o}-D_{i}\right) d_{h}\right]
\end{aligned}
$$

The terms $A_{b p}, A_{t}$, and $A_{f}$ are defined as the unfinned portion of the base plate, total heat sink and pin fins surface areas. Also, $A_{f p}$ is the pin fins projected area, $\mathrm{W}$ and $\mathrm{L}$ are the width and length of the base plate, respectively, $\mathrm{N}$ is the number of fins, $\mathrm{D}_{\mathrm{i}}$ and $\mathrm{D}_{\mathrm{o}}$ are the inner and outer diameter of the pin fins, respectively, $\mathrm{H}_{\mathrm{f}}$ is the height of the pin fin, and $\mathrm{d}_{\mathrm{p}}$ is the perforation diameter.

The average Nusselt number, $\overline{N u}$ based on the length of the base plate, can be expressed as:

$\overline{N u}=\bar{h} L / k$

The Rayleigh number is defined as:

$R a=\frac{\mathrm{g} \beta\left(\mathrm{T}_{s m}-\mathrm{T}_{\infty}\right) L^{3}}{v \alpha}$

The mean surface temperature is defined as:

$\mathrm{T}_{s m}=\left(A_{b p} \mathrm{~T}_{b p}+A_{f} \mathrm{~T}_{f m}\right) / A_{t}$

Where, $\mathrm{T}_{b p}$ and $\mathrm{T}_{f m}$ are the base plate and mean fin temperatures and the thermo physical properties

of the air in the $\overline{N u}$ and Ra numbers expressions are evaluated at the film temperature, $\mathrm{T}_{\mathrm{m}}$, which is given by:

$\mathrm{T}_{m}=\left(\mathrm{T}_{\infty}+\mathrm{T}_{s m}\right) / 2$

Conservation equations:

Mass equation:

$\frac{\partial \mathrm{u}}{\partial \mathrm{x}}+\frac{\partial \mathrm{v}}{\partial \mathrm{y}}+\frac{\partial \mathrm{w}}{\partial \mathrm{z}}=0$

Momentum equation:

$\mathrm{u} \frac{\partial \mathrm{u}}{\partial \mathrm{x}}+\mathrm{v} \frac{\partial \mathrm{u}}{\partial \mathrm{y}}+\mathrm{w} \frac{\partial \mathrm{u}}{\partial \mathrm{z}}=-\frac{1}{\rho} \frac{\partial \mathrm{p}}{\partial \mathrm{x}}+\mu\left(\frac{\partial^{2} \mathrm{u}}{\partial \mathrm{x}^{2}}+\frac{\partial^{2} \mathrm{u}}{\partial \mathrm{y}^{2}}+\frac{\partial^{2} \mathrm{u}}{\partial \mathrm{z}^{2}}\right)$

$\mathrm{u} \frac{\partial \mathrm{v}}{\partial \mathrm{x}}+\mathrm{v} \frac{\partial \mathrm{v}}{\partial \mathrm{y}}+\mathrm{w} \frac{\partial \mathrm{v}}{\partial \mathrm{z}}=-\frac{1}{\rho} \frac{\partial \mathrm{p}}{\partial \mathrm{y}}+\mu\left(\frac{\partial^{2} \mathrm{v}}{\partial \mathrm{x}^{2}}+\frac{\partial^{2} \mathrm{v}}{\partial \mathrm{y}^{2}}+\frac{\partial^{2} \mathrm{v}}{\partial \mathrm{z}^{2}}\right)+\mathrm{g} \beta\left(\mathrm{T}-\mathrm{T}_{\infty}\right)$

$u \frac{\partial w}{\partial x}+v \frac{\partial w}{\partial y}+w \frac{\partial w}{\partial z}=-\frac{1}{\rho} \frac{\partial p}{\partial z}+\mu\left(\frac{\partial^{2} w}{\partial x^{2}}+\frac{\partial^{2} w}{\partial y^{2}}+\frac{\partial^{2} w}{\partial z^{2}}\right)$ 
Energy equation:

$u \frac{\partial T}{\partial x}+v \frac{\partial T}{\partial y}+w \frac{\partial T}{\partial z}=\alpha\left(\frac{\partial^{2} T}{\partial x^{2}}+\frac{\partial^{2} T}{\partial y^{2}}+\frac{\partial^{2} T}{\partial z^{2}}\right)$

2.3 Computational Modeling and Simulation

The computational fluid dynamics modeling, simulation and solving were performed in FLUENT of ANSYS 16.0. In the CFD modeling to carry out fluid analysis, the geometry by design Modeler of ANSYS is created as shown in Fig. 1. The domain was created using "Enclosure" option around the heat sink of size $350 \times 210 \times 110 \mathrm{~mm}$. The following assumptions are taken for the $3 \mathrm{D}$ numerical simulation:

$\checkmark \quad$ Natural convection and radiation heat transfer are considered.

$\checkmark \quad$ Both fluid flow and heat transfer in the simulation study are steady.

$\checkmark \quad$ All air properties were obtained from Holman [20].

$\checkmark \quad$ The thermal conductivity of the heat sink has a constant value.

$\checkmark \quad$ The air flow velocity attached to all boundaries of the domain is zero.

2.4 Mesh independence

Mesh independence as shown in Table 2 was performed by varying the mesh elements from 100,071 to 721,420 hexahedral elements for the SPF heat sink and from 212,188 to 2,688,052 tetrahedral elements for the HPPF heat sink. The optimum grid obtained at 2.2 million of tetrahedral mesh elements. The suitable boundary conditions were attached to the domains shown in Fig. 2. Air and Aluminum were apportioned to the created fluid and solid domain respectively. Activated buoyancy in the $\mathrm{Y}$ direction, chosen viscous model as laminar, pressure-velocity coupling using the SIMPLE algorithm developing by Patankar [21].

\subsection{Results and discussion}

The numerical analysis has been done on the heat sink with solid, hollow and hollow with perforations pin fins and varying the hollow and perforation diameters. Three-dimensional pin fin array models are chosen and simulated by Fluent of ANSYS 16.0. For the heat sink and fluid domain, the temperature contours are explored. The effect of inner-to-outer diameter ratio on $\overline{N u}$ for hollow pin fins heat sink, as well as that effect for the HPPF heat sink, is studied. Finally, the effect of the change in the perforation diameter $\left(\mathrm{d}_{\mathrm{p}}\right)$ on $\overline{N u}$ and the performance of pin fins related to the finning factor $(\Psi)$, which is defined as the total-to-base plate area ratio. The range of Rayleigh number for laminar flow is $10^{5}<\mathrm{Ra}<10^{10}$ [22].

\subsubsection{Model validation}

Fig. 3 compares the variations of $\overline{N u}$ with Ra for the SPF heat sink for the present work and the experimental work by Elshafei [2]. It shows that the maximum deviation in numerical results of $\overline{\mathrm{Nu}}$ equal to $6.4 \%$ at low Ra and the deviation decreased with increasing Ra until reach $0.9 \%$ at high Ra. Fig. 4 compares the variations of the temperature difference between the base plate and the ambient and shows the good matching between the numerical and experimental work.

\subsubsection{Hollow Pin Fin heat sink}

The present work was performed for the heat sink with hollow pin fins with different inner-toouter diameter ratio $\left(D_{i} / D_{0}=1 / 3,1 / 2,2 / 3\right)$ with a staggered arrangement and the equal number and 
height of fins. Over a range of $9.3 \times 10^{6}<\operatorname{Ra}<1.63 \times 10^{7}$, the variation of $\overline{N u}$ with $\mathrm{Ra}$ is examined.

Fig. 5 shows the effect of varying the inner-to-outer diameter ratio and Ra on the $\overline{N u}$. It is observed that $\overline{N u}$ for the SPF heat sink is higher than that for the HPF heat sink, and increasing the innerto-outer diameter ratio $\left(\mathrm{D}_{\mathrm{i}} / \mathrm{D}_{\mathrm{o}}\right), \overline{N u}$ increased but still less than that for solid fin array. It is found that the $\overline{N u}$ for the solid fins is more than that for the hollow fins by $4.1 \%$ for $\left(\mathrm{D}_{\mathrm{i}} / \mathrm{D}_{0}=1 / 3\right), 3.6 \%$ for $\left(\mathrm{D}_{\mathrm{i}} / \mathrm{D}_{0}=1 / 2\right)$ and $2.8 \%$ for $\left(\mathrm{D}_{\mathrm{i}} / \mathrm{D}_{0}=2 / 3\right)$. This may be because of the reduction of the conduction heat transfer rate through the heat sink and that reduction compensate for the increase of the heat transfer coefficient with increasing $\left(\mathrm{D}_{\mathrm{i}} / \mathrm{D}_{\mathrm{o}}\right)$ as discussed in Huang [18] which reported that $\bar{h}$ decreases with increasing finning factor $\Psi$. It is also verified by the temperature difference variation between the base plate and the ambient with the heat flux that shown in Fig. 6. Also, the temperature contours of solid and hollow pin fins are shown in Fig. 7.

\subsubsection{Hollow Perforated Pin Fin heat sink}

Fig. 8 shows the average $\overline{N u}$ variations with Ra for the heat sink with varying the inner-to-outer diameter ratio $\left(\mathrm{D}_{\mathrm{i}} / \mathrm{D}_{\mathrm{o}}\right)$ at the same perforation diameter $\left(\mathrm{d}_{\mathrm{p}}=3.5 \mathrm{~mm}\right)$. It is observed that $\overline{N u}$ increases with increasing $\mathrm{D}_{\mathrm{i}} / \mathrm{D}_{0}$, which results from the increase of the coefficient of heat transfer by reason of the increase of the intensity of induced plumes with higher $\mathrm{D}_{\mathrm{i}} / \mathrm{D}_{0}$. But at $\mathrm{D}_{\mathrm{i}} / \mathrm{D}_{0}$ is larger than $1 / 2, \overline{N u}$ decreases again. As, it is found that $\overline{N u}$ for the HPPF with $\left(\mathrm{D}_{\mathrm{i}} / \mathrm{D}_{0}=1 / 3\right)$ is more than that for the SPF by $1.01 \%$ and for HPPF with $\left(\mathrm{D}_{\mathrm{i}} / \mathrm{D}_{\mathrm{o}}=1 / 2\right)$ by $2.76 \%$. But, $\overline{N u}$ for $\left(\mathrm{D}_{\mathrm{i}} / \mathrm{D}_{\mathrm{o}}\right.$ $=2 / 3$ ) is less than that for SPF by $0.96 \%$. It may be because of the reduction of the heat transfer by conduction from the heat sink is more than the increase of heat transfer due to induced plumes effect.

The temperature contours of the HPPF heat sinks with constant $d_{p}$ varying $D_{i} / D_{o}(1 / 3,1 / 2,2 / 3)$ at constant heat flux $\mathrm{Q}=60 \mathrm{~W}$ are shown in Fig. 9. The variations $\overline{\mathrm{Nu}}$ with Ra for the heat sink when varying $d_{p}(3.5,4,5$ and $6 \mathrm{~mm})$ and fixed $D_{i} / D_{o}$ equal to $1 / 2$ to study the effect of increasing the perforation diameter on the heat sink performance is shown in Fig. 10. It is found that with increasing $\mathrm{d}_{\mathrm{p}}$, the average $\overline{N u}$ slightly increases. That may be due to the circulation of air through the HPPF heat sink which increases $\bar{h}$ so increases $\overline{N u}$. From the present data, it is concluded that the HPPF heat sink with $\left(D_{i} / D_{o}=1 / 2\right.$ and $\left.d_{p}=6 \mathrm{~mm}\right)$ give the maximum system performance of the other samples. The temperature contours of the (HPPF) heat sinks with constant $\mathrm{D}_{\mathrm{i}} / \mathrm{D}_{\mathrm{o}}$ varying $\mathrm{d}_{\mathrm{p}}(3.5,4,5,6 \mathrm{~mm})$ at constant heat flux $\mathrm{Q}=60 \mathrm{~W}$ are shown in Fig. 11. Fig. 12 shows the varying between the SPF, HPF $\left(D_{i} / D_{o}=1 / 3\right)$ and the HPPF heat sink with $\left(D_{i} / D_{o}=1 / 3\right.$ and $\left.d_{p}=3.5 \mathrm{~mm}\right)$ and represents that $\overline{\mathrm{Nu}}$ for the SPF heat sink is higher than that for the HPF heat sink by $5.5 \%$ because of increasing the heat transfer surface area and is lower than that for the HPPF heat sink by $1.01 \%$ because of circulation of air through pin fins that increasing intensity of induced plumes. So, it is preferable to produce the hollow/perforated fins than the solid ones to reduce the amount of material using in it. 


\section{Conclusion}

In this paper, a numerical study of 3-dimensional laminar fluid flow and natural convection heat transfer over an array of solid, hollow and hollow/perforated fins are made. Over a range of Rayleigh number from $9.3 \times 10^{6}$ to $1.63 \times 10^{7}$, the following conclusions have been reached:

1. For all cases of heat sink studied, $\overline{N u}$ increases with increasing Ra.

2. $\overline{N u}$ for solid pin fin heat sink is higher than that for hollow pin fin heat sink.

3. $\overline{\mathrm{Nu}}$ for hollow/perforated pin fin heat sink is higher than that for solid pin fin heat sink.

4. Maximum system performance may be achieved with hollow/perforated pin fins when the inner-to-outer diameter ratio and perforation diameter are optimized. With the present configuration of pin fins, a sample of fins with $\mathrm{D}_{\mathrm{i}} / \mathrm{D}_{\mathrm{o}}=1 / 2$ and $\mathrm{d}_{\mathrm{p}}=6 \mathrm{~mm}$ is the best sample with high thermal performance.

5. It is preferable to use the hollow/perforated fins to reduce the amount of mass used to manufacture heat sinks, especially those who rely on natural convection.

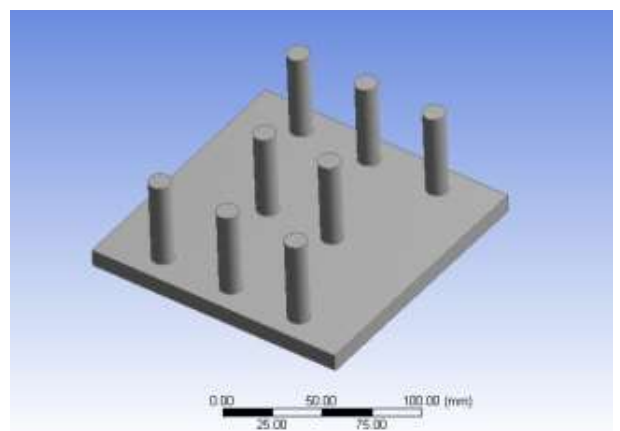

(a)

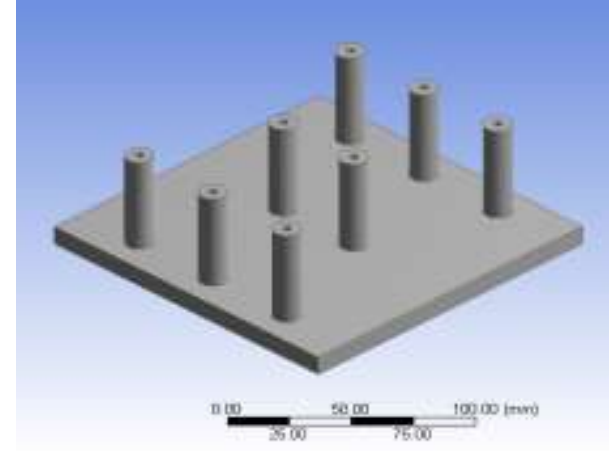

(b)

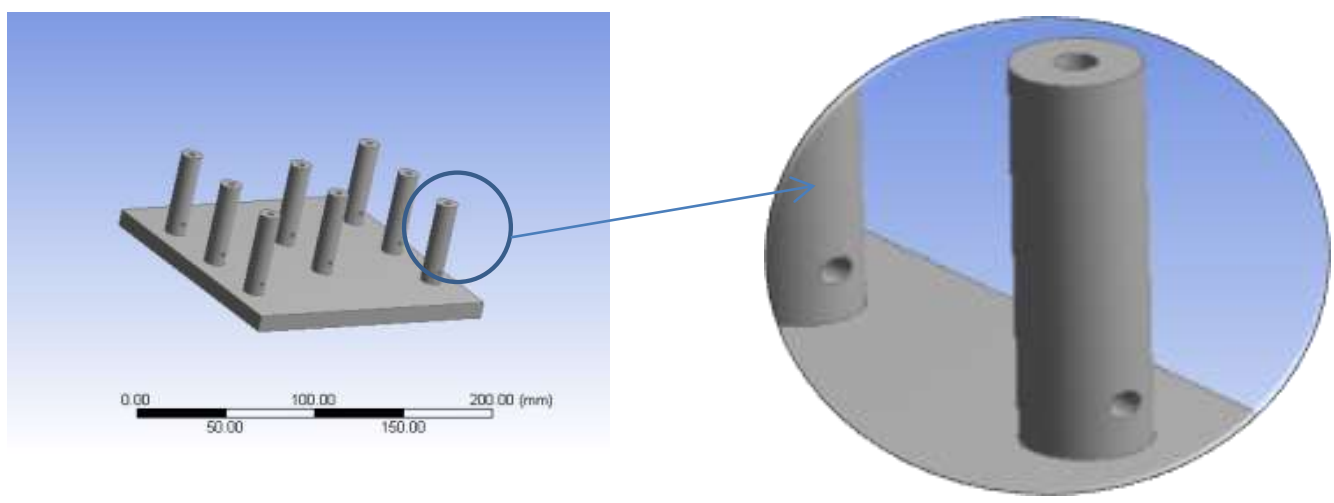

(C) 


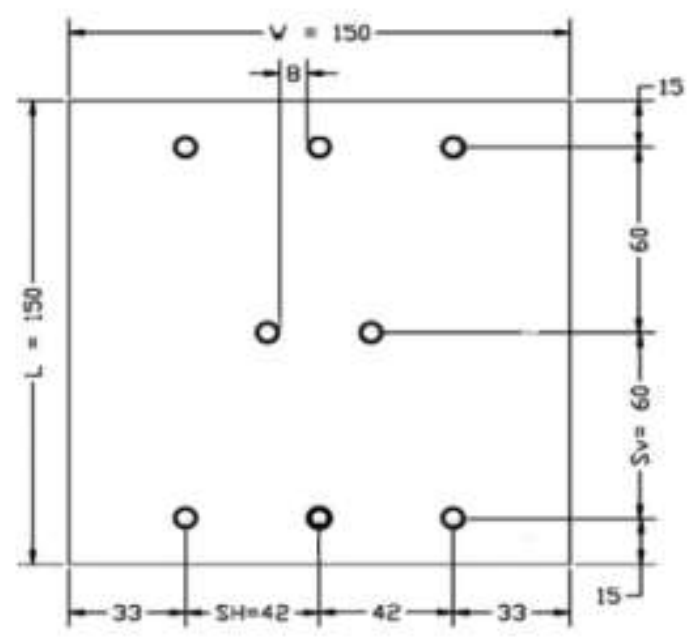

(d)

Fig. 1. A schematic of pin fin heat sink: (a) solid fins; (b) hollow fins; (c) hollow/perforated fins; (d) top view of heat sink.

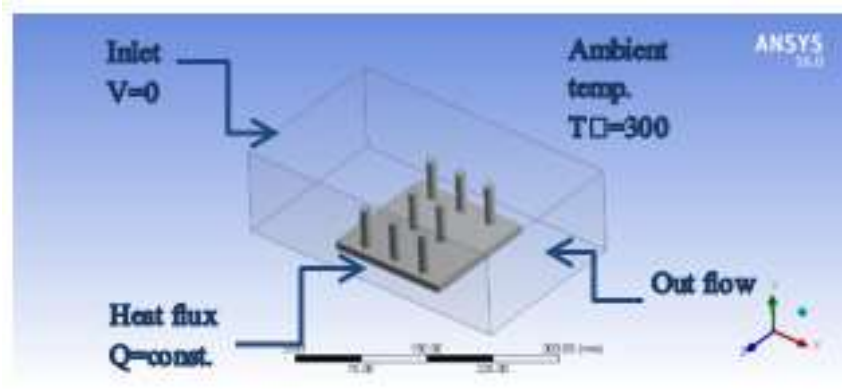

Fig. 2. The boundary conditions of pin fin heat sink.

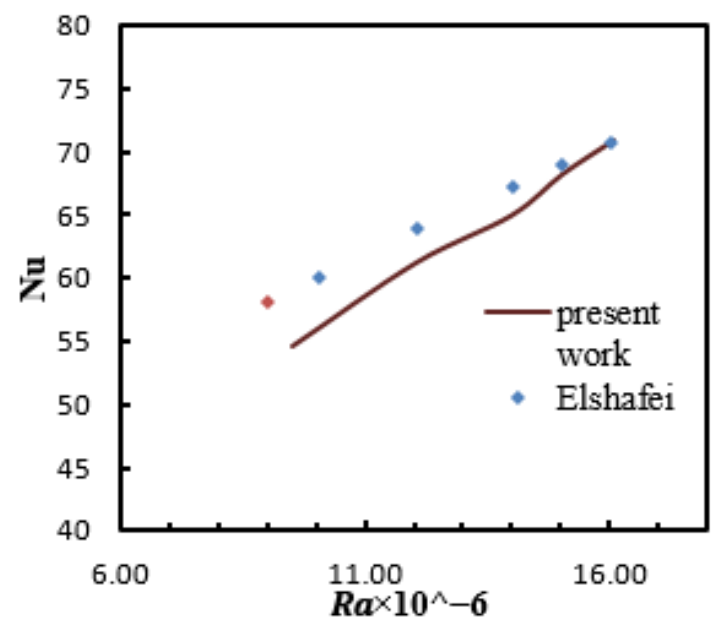

Fig. 3. Comparison of $\overline{\mathrm{Nu}}$ variations with Ra for the present work and the data given by El-shafei[2] for the solid pin fin heat sink.

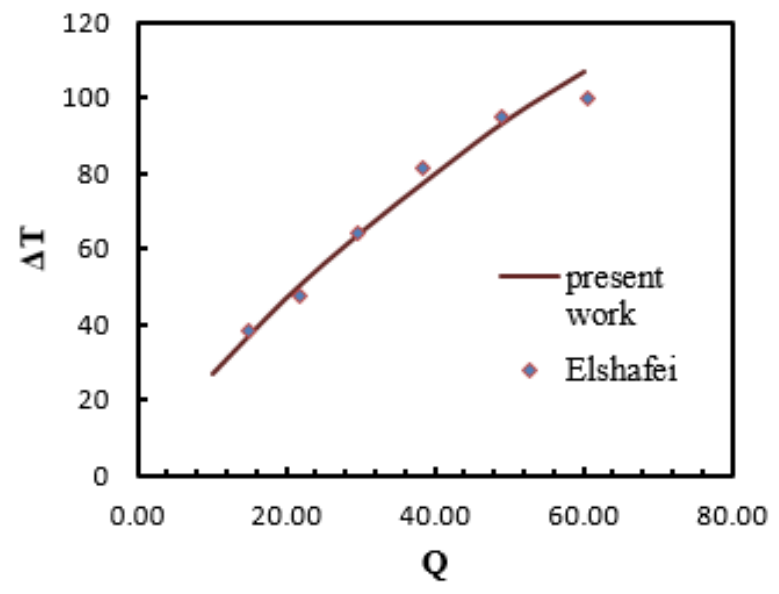

Fig.4. Comparison of temperature differences variations with heat flux for the present work and the data given by El-shafei [2] for the solid pin fin heat sink. 


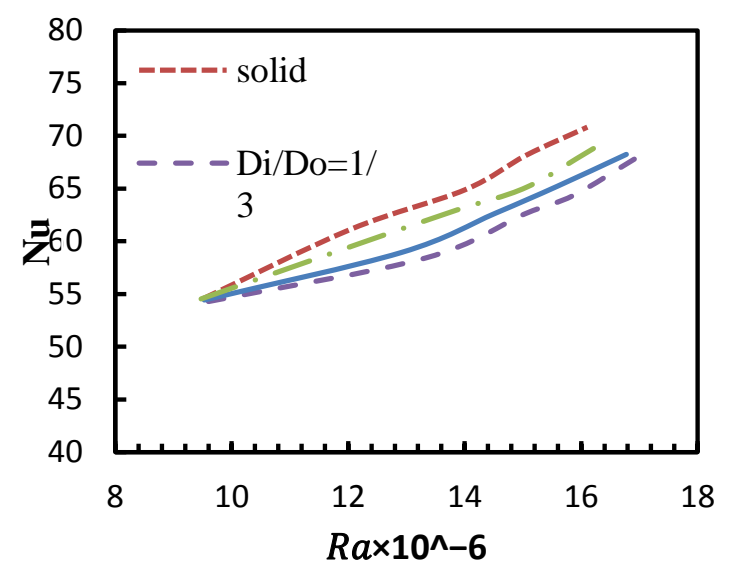

Fig. 5. $\overline{\mathrm{Nu}}$ versus Ra of solid and hollow pin fin array with varying $\mathrm{D}_{\mathrm{i}} / \mathrm{D}_{\mathrm{o}}(1 / 3,1 / 2,2 / 3)$.

Solid $\left(\mathrm{D}_{\mathrm{i}} / \mathrm{D}_{0}=0\right)$

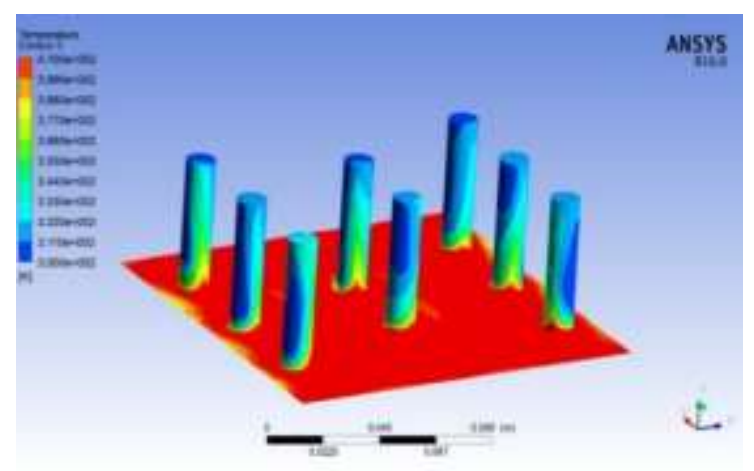

$\mathrm{D}_{\mathrm{i}} / \mathrm{D}_{\mathrm{o}}=1 / 2$

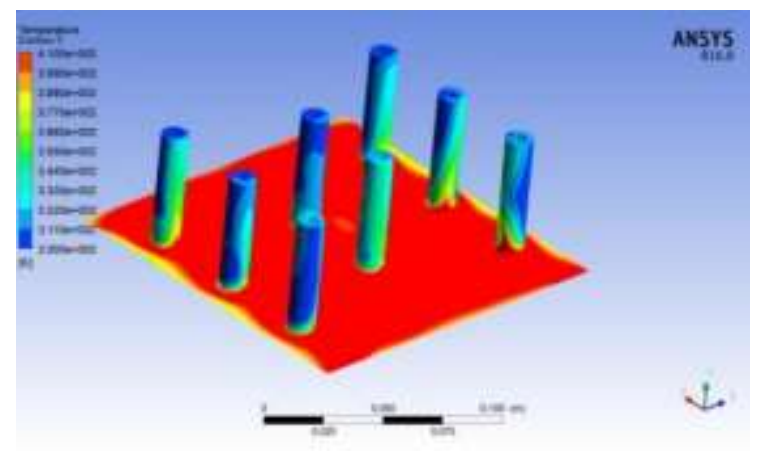

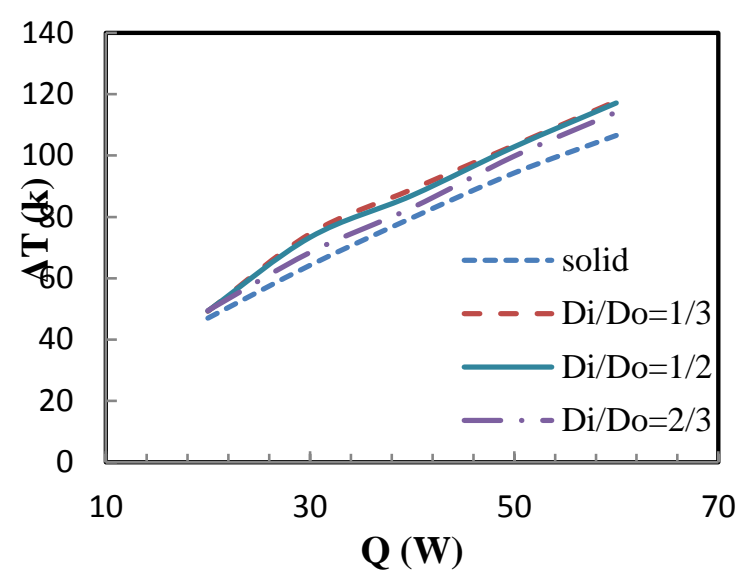

Fig. 6. Temperature differences versus heat flux of solid and hollow pin fin array with varying $D_{\mathrm{i}} / \mathrm{D}_{0}$ $(1 / 3,1 / 2,2 / 3)$.

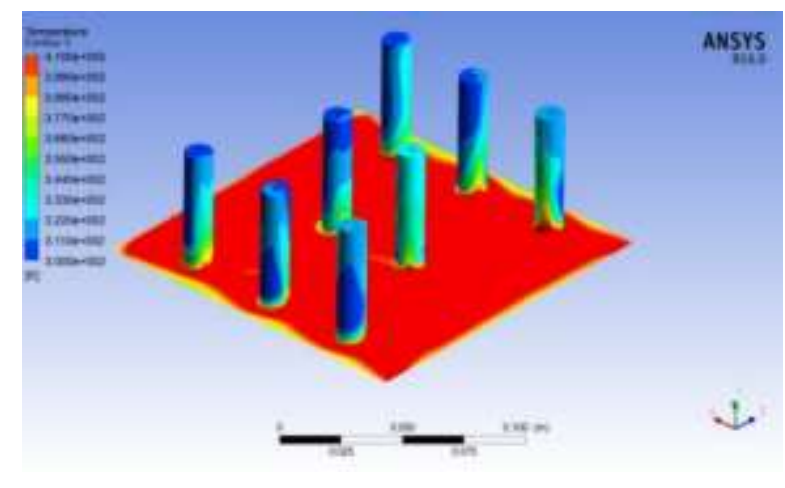

$D_{i} / D_{0}=2 / 3$

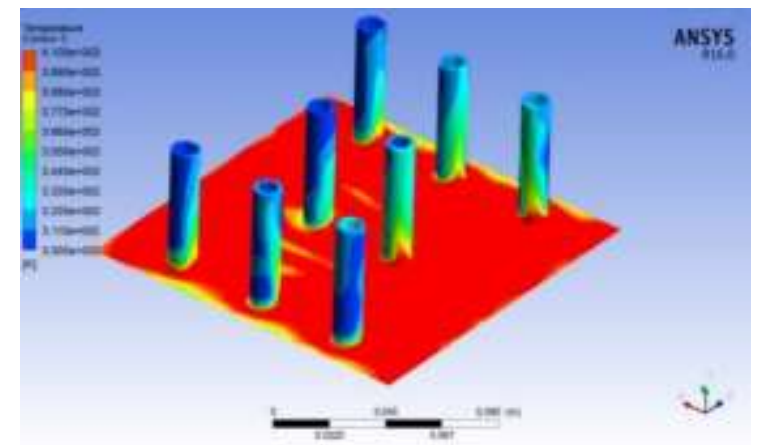

Fig. 7. Temperature contours of solid and hollow pin fin array with varying $D_{i} / D_{o}(0,1 / 3,1 / 2,2 / 3)$ at constant heat flux $\mathrm{Q}=60 \mathrm{~W}$. 


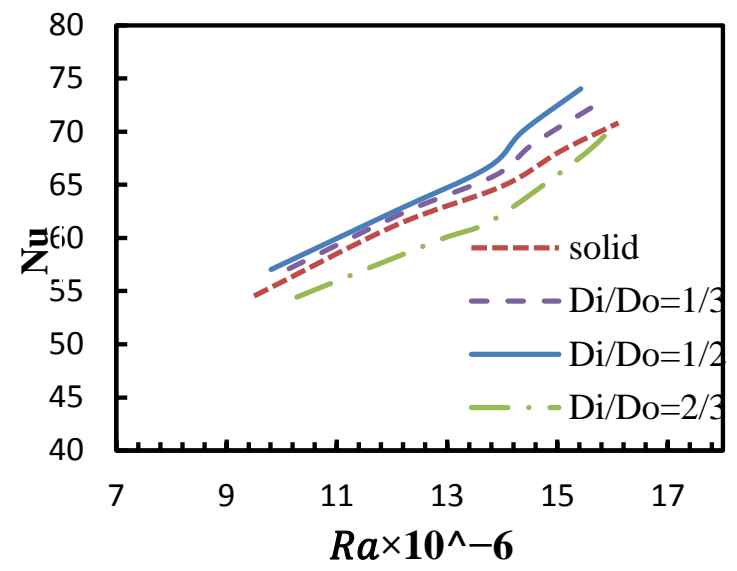

Fig. 8. $\overline{\mathrm{Nu}}$ versus Ra of solid and hollow/perforated pin fin array with constant $d_{p}=3.5 \mathrm{~mm}$ and varying $D_{i} / D_{o}$ $(1 / 3,1 / 2,2 / 3)$.

$\mathrm{D}_{\mathrm{i}} / \mathrm{D}_{\mathrm{o}}=1 / 3$ and $\mathrm{d}_{\mathrm{p}}=3.5 \mathrm{~mm}$

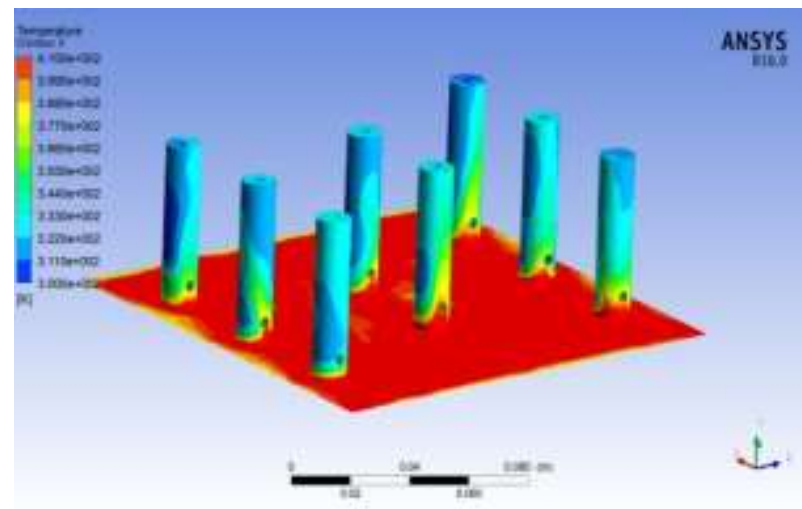

$\mathrm{D}_{\mathrm{i}} / \mathrm{D}_{\mathrm{o}}=1 / 2$ and $\mathrm{d}_{\mathrm{p}}=3.5 \mathrm{~mm}$

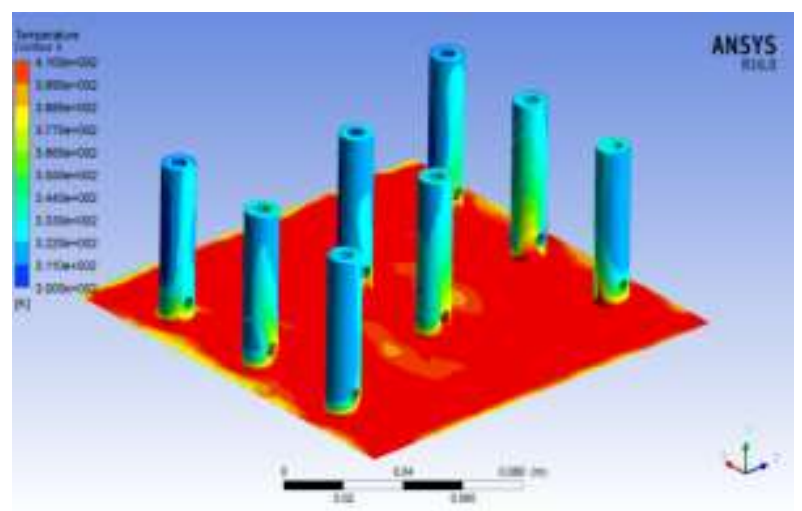

$\mathrm{D}_{\mathrm{i}} / \mathrm{D}_{\mathrm{o}}=1 / 2$ and $\mathrm{d}_{\mathrm{p}}=3.5 \mathrm{~mm}$

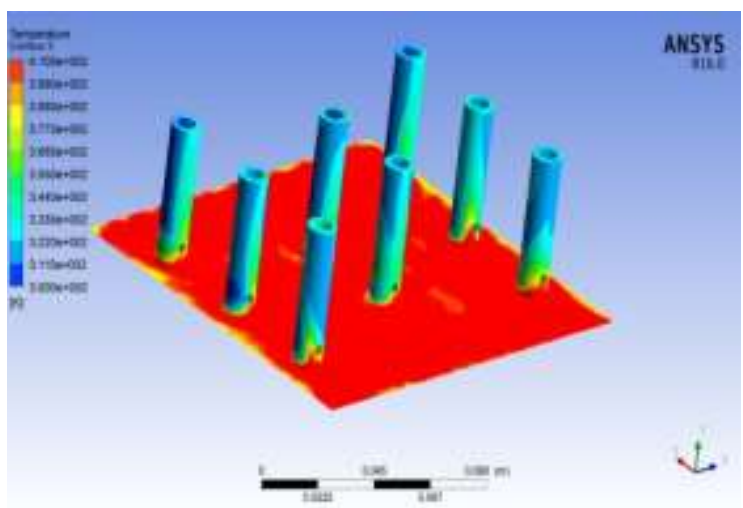

Fig. 9. Temperature contours of hollow/perforated pin fin array with constant $d_{p}=3.5 \mathrm{~mm}$ and varying $D_{i} / D_{o}(1 / 3,1 / 2$, $2 / 3$ ) at constant heat flux $\mathrm{Q}=60 \mathrm{~W}$. 


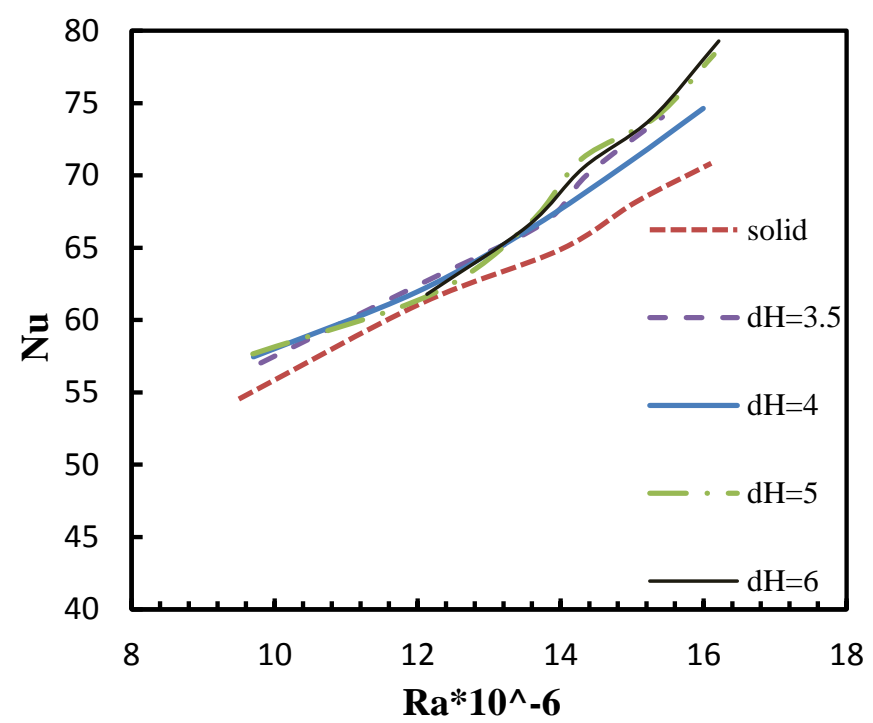

Fig.10. $\overline{\boldsymbol{N u}}$ versus $R$ a of solid and hollow/perforated pin fin array with constant $D_{i} / D_{o}=1 / 2$ and varying $d_{p}(3.5$, 4, 5, $6 \mathrm{~mm})$.

$\mathrm{D}_{\mathrm{i}} / \mathrm{D}_{\mathrm{o}}=1 / 2$ and $\mathrm{d}_{\mathrm{p}}=3.5 \mathrm{~mm}$

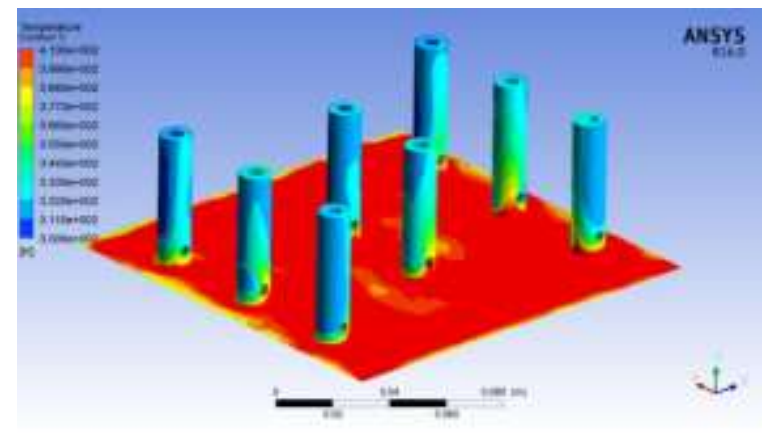

$\mathrm{D}_{\mathrm{i}} / \mathrm{D}_{\mathrm{o}}=1 / 2$ and $\mathrm{d}_{\mathrm{p}}=5 \mathrm{~mm}$

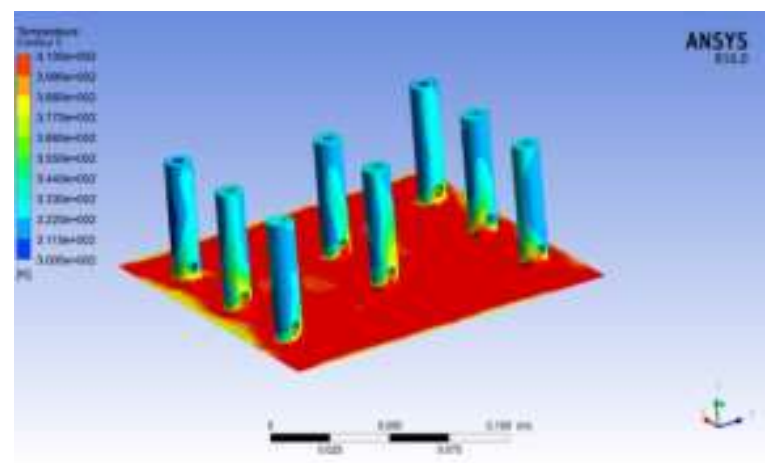

$\mathrm{D}_{\mathrm{i}} / \mathrm{D}_{\mathrm{o}}=1 / 2$ and $\mathrm{d}_{\mathrm{p}}=4 \mathrm{~mm}$

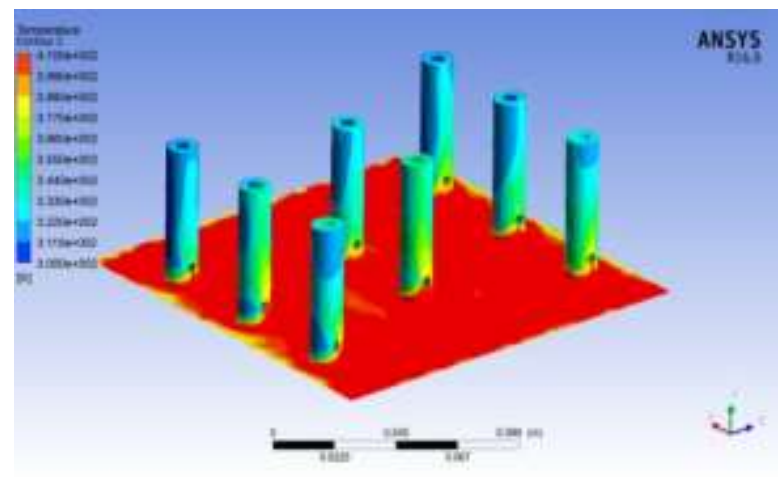

$\mathrm{D}_{\mathrm{i}} / \mathrm{D}_{\mathrm{o}}=1 / 2$ and $\mathrm{d}_{\mathrm{p}}=6 \mathrm{~mm}$

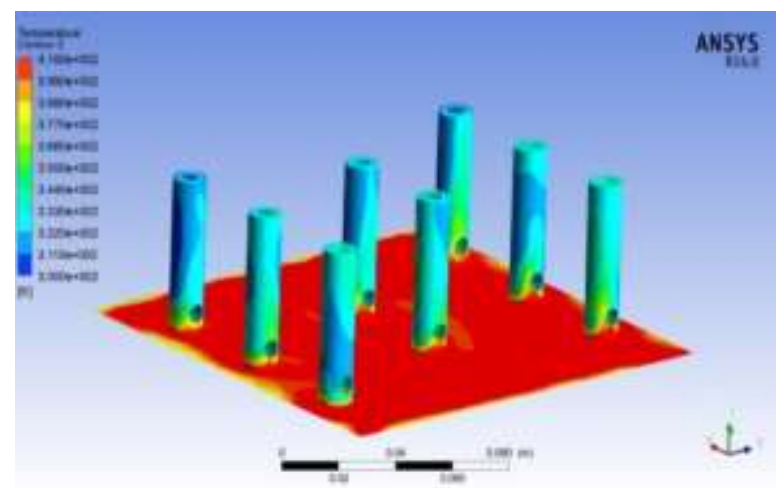

Fig. 11. Temperature contours of hollow/perforated pin fin array with constant $D_{i} / D_{0}=1 / 2$ and varying $d_{p}(3.5,4,5,6$ $\mathrm{mm}$ ) at constant heat flux $\mathrm{Q}=60 \mathrm{~W}$ 


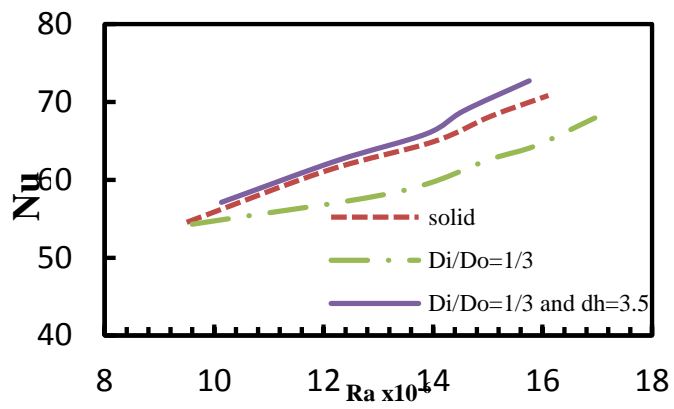

Fig.12. $\overline{\boldsymbol{N u}}$ versus Ra of solid, hollow and hollow/perforated pin fin array.

Table 1: Geometric details of investigated heat sink modules.

\begin{tabular}{|c|c|c|c|c|c|c|c|c|c|}
\hline & Sample & $\begin{array}{c}\mathrm{S}_{\mathrm{h}} \\
\mathbf{m m}\end{array}$ & $\begin{array}{c}S_{\mathrm{v}} \\
\mathbf{m m}\end{array}$ & $\begin{array}{l}\text { W,L } \\
\text { mm }\end{array}$ & $\begin{array}{c}\mathbf{H}_{\mathrm{f}} \\
\mathbf{m m}\end{array}$ & $\begin{array}{c}D_{0} \\
\text { mm }\end{array}$ & $\begin{array}{c}D_{i} \\
\mathbf{m m}\end{array}$ & $\begin{array}{c}\mathbf{d}_{\mathrm{p}} \\
\mathbf{m m}\end{array}$ & $\begin{array}{c}\Psi \\
\left(\mathbf{A}_{t} / \mathbf{A}_{\mathrm{bp}}\right)\end{array}$ \\
\hline : & 1 & 42 & 60 & 150 & 50 & 12 & 0 & 0 & 1.74049 \\
\hline \multirow{3}{*}{ 를 } & 2 & 42 & 60 & 150 & 5 & 12 & 4 & 0 & 1.96421 \\
\hline & 3 & 42 & 60 & 150 & 50 & 12 & 6 & 0 & 2.06811 \\
\hline & 4 & 42 & 60 & 150 & 50 & 12 & 8 & 0 & 2.16587 \\
\hline \multirow{3}{*}{ 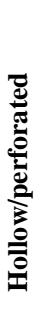 } & 5 & 42 & 60 & 150 & 50 & 12 & 4 & 3.5 & 1.99665 \\
\hline & 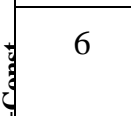 & 42 & 60 & 150 & 50 & 12 & 6 & 3.5 & 2.09231 \\
\hline & 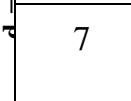 & 42 & 60 & 150 & 50 & 12 & 8 & 3.5 & 2.18187 \\
\hline \multirow{3}{*}{ 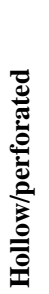 } & 8 & 42 & 60 & 150 & 50 & 12 & 6 & 4 & 2.09577 \\
\hline & 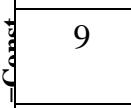 & 42 & 60 & 150 & 50 & 12 & 6 & 5 & 2.10268 \\
\hline & 10 & 42 & 60 & 150 & 50 & 12 & 6 & 6 & 2.10959 \\
\hline
\end{tabular}

Table 2: Mesh independence using heat transfer coefficient for the solid and hollow/perforated pin fin heat sinks.

\begin{tabular}{|c|c|c|c|c|c|c|c|c|}
\hline \multicolumn{7}{|c|}{ Solid Pin Fins } \\
\hline $\begin{array}{c}\text { No. of } \\
\text { Elements }\end{array}$ & 100071 & 120171 & 137370 & 162113 & 212188 & 386180 & 500444 & 721420 \\
\hline $\bar{h}$ & 10.8748 & 10.93237 & 11.1781 & 11.28464 & 11.32015 & 11.3894 & 11.4157 & 11.4139 \\
\hline \multicolumn{7}{|c|}{ Hollow/Perforated Pin Fins } \\
\hline $\begin{array}{c}\text { No. of } \\
\text { Elements }\end{array}$ & 212188 & 374681 & 899124 & 1118618 & 1643356 & 2001548 & 2217066 & 2688052 \\
\hline $\bar{h}$ & 11.0142 & 11.1548 & 11.3124 & 11.46141 & 11.59741 & 11.7284 & 11.8121 & 11.81521 \\
\hline
\end{tabular}




\section{References}

[1] A. H. Alessa, A. M. Maqableh, and S. Ammourah, "Enhancement of natural convection heat transfer from a fin by rectangular perforations with aspect ratio of two," vol. 4, no. 10, pp. 540-547, 2009.

[2] E. A. M. Elshafei, "Natural convection heat transfer from a heat sink with hollow/perforated circular pin fins," Energy, vol. 35, no. 7, pp. 2870-2877, 2010.

[3] S. D. Bahadure, G. D. Gosavi, and B. Ambedkar, "Enhancement of Natural Convection Heat Transfer from Perforated Fin Abstract :," vol. 5013, no. 3, pp. 531-535, 2014.

[4] M. Ahmed, A. Jabbar, and N. Khalifa, "Natural convection heat transfer from a heat sink with fins of different configuration," Int. J. Innov. Appl. Stud., vol. 9, no. 3, pp. 1043-1047, 2014.

[5] U. V. Awasarmol and A. T. Pise, "An experimental investigation of natural convection heat transfer enhancement from perforated rectangular fins array at different inclinations," Exp. Therm. Fluid Sci., vol. 68, pp. 145-154, 2015.

[6] M. I. Al-widyan and A. Al-shaarawi, "Numerical Investigation of Heat Transfer Enhancement for a Perforated Fin in Natural Convection," vol. 2, no. 1, pp. 175-184, 2012.

[7] S. Baskaya, M. Sivrioglu, and M. Ozek, "Parametric study of natural convection heat transfer from horizontal rectangular fin arrays," Int. J. Therm. Sci., vol. 39, no. 8, pp. 797-805, 2000.

[8] A. H. AlEssa and M. I. Al-Widyan, "Enhancement of natural convection heat transfer from a fin by triangular perforation of bases parallel and toward its tip," Appl. Math. Mech. (English Ed., vol. 29, no. 8, pp. 1033-1044, 2008.

[9] D. H. S, K. N. Vijaykumar, D. Kavita, S. Indira, G. College, and N. Mumbai, "Natural Convection Heat Transfer Flow Visualization of Perforated Fin Arrays By Cfd Simulation," pp. 483-490, 2013.

[10] J. R. Welling and C. B. Wooldridge, "Natural Convection Heat Transfer Coefficients From Rectangular Vertical Fins," J. Heat Transf., vol. 87, no. 4, pp. 439-444, 1965.

[11] J. B. Chaddock, "Free convection heat transfer from vertical rectangular fin arrays," ASHRAE J., vol. 12, no. 1, pp. 53-60, 1970.

[12] S. Naik, S. D. Probert, and C. I. Wood, "Natural-convection characteristics of a horizontally-based vertical rectangular fin-array in the presence of a shroud," Appl. Energy, vol. 28, no. 4, pp. 295-319, 1987.

[13] C. W. Leung and S. D. Probert, "Heat exchanger design: Optimal thickness (under natural convective conditions) of vertical rectangular fins protruding upwards from a horizontal rectangular base," Appl. Energy, vol. 29, no. 4, pp. 299-306, 1988.

[14] Y. M. Ko, C. W. Leung, and S. D. Probert, "Steady-state free-convective cooling of heat exchangers with vertical rectangular fins: Effect of fin material," Appl. Energy, 1989.

[15] E. M. Sparrow and S. B. Vemuri, "Orientation effects on natural convection/radiation heat transfer from pin-fin arrays," Int. J. Heat Mass Transf., vol. 29, no. 3, pp. 359368, 1986.

[16] M. E. Alessio and D. A. Kaminski, "Natural convection and radiation heat transfer from an array of inclined pin fins," ASME Trans. J. Heat Transf., vol. 111, no. February 1989, pp. 197-199, 1989.

[17] A. I. Zografos and J. Edward Sunderland, "Natural convection from pin fin arrays," Exp. Therm. Fluid Sci., vol. 3, no. 4, pp. 440-449, 1990.

[18] R. T. Huang, W. J. Sheu, and C. C. Wang, "Orientation effect on natural convective performance of square pin fin heat sinks," Int. J. Heat Mass Transf., vol. 51, no. 9-10, pp. 2368-2376, 2008. 
[19] R. Bahadur and A. Bar-Cohen, "Thermal design and optimization of natural convection polymer pin fin heat sinks," IEEE Trans. Components Packag. Technol., vol. 28, no. 2, pp. 238-246, 2005.

[20] J. P. Holman, Heat Transfer, Sixth edit. McGraw-Hill Book Company, 1986.

[21] S. Patankar, Numerical Heat Transfer and Fluid Flow. CRC press, 1980.

[22] D. P. Bergman, T.L., Lavine, A.S., Incropera, F.P. and Dewitt, Fundamentals of heat and mass transfer. 2011. 